\title{
COMPARAÇÃO ENTRE TRÊS SISTEMAS DE NOTAÇÃO DA CONFIGURAÇÃO DE MÃO COM BASE EM DADOS DA LIBRAS
}

\section{COMPARISON BETWEEN THREE HAND CONFIGURATION NOTATION SYSTEMS BASED ON LIBRAS DATA}

\author{
Elisane Conceição Alecrim* \\ André Nogueira Xavier ${ }^{* *}$
}

\begin{abstract}
Resumo
A configuração de mão é um dos parâmetros articulatórios com base no qual os sinais podem ser analisados. Ela se refere, especificamente, aos diferentes estados das juntas dos dedos, potencialmente distintivos, mas também sujeitos à grande variação intra e intersujeito. Neste trabalho, são comparados três sistemas de notação propostos para esse parâmetro, o de Stokoe, o de Liddell e Johnson e o de Johnson e Liddell, com vistas a demonstrar, com base em dados da libras, que o terceiro deles é mais apropriado para a análise fonética das línguas sinalizadas. Os dados analisados se referem a uma das três produções de 26 dos 60 sinais originalmente coletados por Xavier e Barbosa (2014) de 12 sujeitos surdos (seis homens e seis mulheres) da cidade de São Paulo. O critério de seleção desses sinais foi a presença da configuração de mão em B (dedos abertos e unidos pelas laterais) e da configuração de mão em 5 (dedos abertos e espalmados). Com isso, 185 produções foram selecionadas e analisadas. Os resultados indicam que o sistema de Stokoe tem caráter mais fonológico, o de Johnson e Liddell, um caráter mais fonético e o de Liddell e Johnson, um caráter intermediário entre os dois primeiros.
\end{abstract}

Palavras-chave: Notação. Configuração de mão. Fonética.

\section{Introdução}

A configuração de mão $(\mathrm{CM})$, um dos parâmetros articulatórios dos sinais, itens lexicais das línguas sinalizadas, se refere, especificamente, aos diferentes estados das juntas dos dedos. Embora esses estados sejam potencialmente distintivos, eles também estão sujeitos à grande variação intra e intersujeito. Alecrim e Xavier (2017, a sair) é, até o momento, o único estudo acerca da variação fonético-fonológica desse parâmetro na libras que se baseia no modelo de análise sublexical de Liddell

\footnotetext{
* Licenciada em Letras Libras pela Universidade Federal do Paraná. alecrim.ely@gmail.com

** Doutorado em Línguística pela Unicamp. Professor do Curso de Letras Libras da Universidade Federal do Paraná. andrexavier@ufpr.br
} 
e Johnson (1989). Esse modelo se mostrou um avanço em relação ao de Stokoe (1960), ao propor, no lugar de um tratamento holístico da CM, uma análise componencial para esse parâmetro por meio de traços. Além disso, esse modelo também se particulariza por propor que os dedos indicador, médio, anelar e mínimo atuam em conjunto e separadamente do polegar, justamente por este apresentar maior independência articulatória.

Apesar de os resultados de Alecrim e Xavier reforçarem a ideia defendida por Liddell e Johnson quanto à necessidade de descrever a $\mathrm{CM}$ por meio de feixes de traços, eles também mostraram limitações do referido modelo, semelhantes às apontadas pelos próprios autores em sua proposta recente de descrição desse parâmetro (JOHNSON; LIDDELL, 2011, 2012). Nessa nova versão, a independência articulatória de cada dedo, responsável pela grande variação na $\mathrm{CM}$ observada em usos concretos por Alecrim e Xavier, é contemplada através da possibilidade de se descrever separadamente o estado de cada uma das juntas de cada um dos dedos.

Este trabalho tem como objetivo demonstrar que o sistema de notação da CM proposto mais recentemente por Johnson e Liddell é mais apropriado para a análise fonética das línguas sinalizadas. Essa demonstração será realizada através da comparação de três sistemas de notação propostos para esse parâmetro, a saber, o de Stokoe (1960), o de Liddell e Johnson (1989) e o de Johnson e Liddell (2011 e 2012), por meio de dados da libras contendo as configurações de mão em B (dedos distendidos e unidos) e em 5 (dedos distendidos e espalmados).

Esses três sistemas de notação da configuração de mão são apresentados na seção 2. Na seção 3, descrevemos a metodologia de coleta dos dados, bem como de sua análise. Por fim, na seção 4, apresentamos os resultados obtidos e, na seção 5, nossas conclusões.

\section{Revisão de literatura}

\subsection{Sistema de notação da configuração de mão de Willian Stokoe (1960)}

Stokoe (1960) é considerado o pai da linguística das línguas de sinais. Ele foi o primeiro a demonstrar que a língua de sinais americana, ASL ${ }^{\mathrm{i}}$, apresenta uma estrutura linguística. Especificamente, Stokoe demonstrou que o sinal é dividido em três partes: configuração de mão (CM), localização (LOC) e movimento (MOV). Ele identificou diferentes especificações para cada uma dessas partes, às quais chamou de quiremas em analogia aos fonemas das línguas orais. Além disso, ele criou um sistema de notação para essas especificações, o qual foi usado no Dicionário da língua de sinal americana com base em princípios linguísticos, publicado juntamente com Carl Croneberg e Dorothy 
Casterline em 1965. Na proposta de Stokoe, a CM é representada globalmente por meio de um único símbolo. Como mostra o Quadro 1, o autor propôs 19 símbolos para o registro das configurações da ASL.

Quadro 1. Símbolos propostos por Stokoe para o registro das CM da ASL

\begin{tabular}{|c|c|c|c|}
\hline \multicolumn{4}{|c|}{ Configuração de mão símbolos, alguns também usados como localização } \\
\hline A & $\begin{array}{l}\text { Mão compacta, punho; pode ser como as } \\
\text { letras 'a', s ', ou ' t ' do alfabeto manual. }\end{array}$ & $\mathrm{L}$ & $\begin{array}{l}\text { Mão de ângulo; polegar, dedo indicador em ângulo } \\
\text { reto, outros dedos, normalmente dobrados e } \\
\text { tocando a palma. }\end{array}$ \\
\hline B & Mão plana. & 3 & $\begin{array}{l}\text { Polegar e os dois primeiros dedos espalmados, } \\
\text { como o número ' } 3 \text { ', da numeração manual. }\end{array}$ \\
\hline 5 & $\begin{array}{l}\text { Dedos e polegar espalmados como o número } \\
\text { '5' de numeração manual. }\end{array}$ & $\mathrm{O}$ & $\begin{array}{l}\text { Mão cônica; dedos curvados e espremidos juntos ao } \\
\text { longo do polegar; pode ser como 'o' do alfabeto } \\
\text { manual. }\end{array}$ \\
\hline $\mathrm{C}$ & $\begin{array}{l}\text { Mão curva; pode ser mais aberta ou como o 'c' } \\
\text { do alfabeto manual. }\end{array}$ & $\mathrm{R}$ & $\begin{array}{l}\text { Dedo do meio cruzando o dedo indicador, como o } \\
\text { 'r' do alfabeto manual. }\end{array}$ \\
\hline $\mathrm{E}$ & $\begin{array}{l}\text { Mão contraída; como 'e' do alfabeto } \\
\text { manual ou como uma garra. }\end{array}$ & $\mathrm{V}$ & $\begin{array}{l}\text { Mão de "vitória"; indicador e dedo do meio } \\
\text { distendidos e espalmados. }\end{array}$ \\
\hline $\mathrm{F}$ & $\begin{array}{l}\text { Polegar e dedo indicador se tocando pelas } \\
\text { pontas e demais dedos abertos. }\end{array}$ & $\mathrm{W}$ & $\begin{array}{l}\text { Dedos indicador, médio e anelar distendidos e } \\
\text { espalmados, e polegar tocando a unha do dedo } \\
\text { mínimo. }\end{array}$ \\
\hline G & 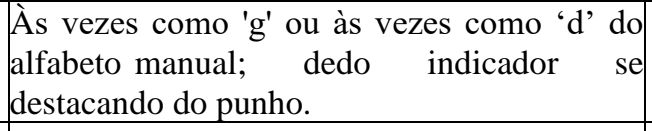 & $\mathrm{X}$ & $\begin{array}{l}\text { Dedo indicador em gancho e demais dedos } \\
\text { fechados; a ponta do polegar pode tocar a ponta } \\
\text { do polegar. }\end{array}$ \\
\hline $\mathrm{H}$ & $\begin{array}{l}\text { Indicador e dedo do meio distendidos lado- a- } \\
\text { lado. }\end{array}$ & Y & $\begin{array}{l}\text { Mão em "chifres"; polegar e o dedo mínimo } \\
\text { distendidos e espalmados, demais fechados; ou } \\
\text { dedos indicador e mínimo distendidos e } \\
\text { paralelos. }\end{array}$ \\
\hline I & Dedo mínimo distendido e demais fechados. & 8 & $\begin{array}{l}\text { (Variante de Y); dedo médio dobrado, demais } \\
\text { abertos e espalmados, o polegar pode tocar a } \\
\text { ponta do dedo médio. }\end{array}$ \\
\hline $\mathrm{K}$ & $\begin{array}{l}\text { Parecido com a letra } \mathrm{G} \text { do alfabeto manual, } \\
\text { exceto pelo toque do polegar na falange media } \\
\text { do dedo médio; como 'k' e 'p' do alfabeto } \\
\text { manual }\end{array}$ & & \\
\hline
\end{tabular}

Fonte: Traduzida de Stokoe (1960, p.27)

Pode-se considerar a proposta de notação da CM de Stokoe como fonológica, porque ela ignora diferenças entre as CM supostamente não distintivas na ASL. Por exemplo, na visão do autor, as CM B e 5 não se referem apenas à mão plana e à mão espalmada, respectivamente. Como se pode ver na Figura 1, cada uma delas se refere a um conjunto de configurações qualitativamente diferentes. 
Figura 1. CM 'B' e '5' de acordo com o sistema do Stokoe (1960)

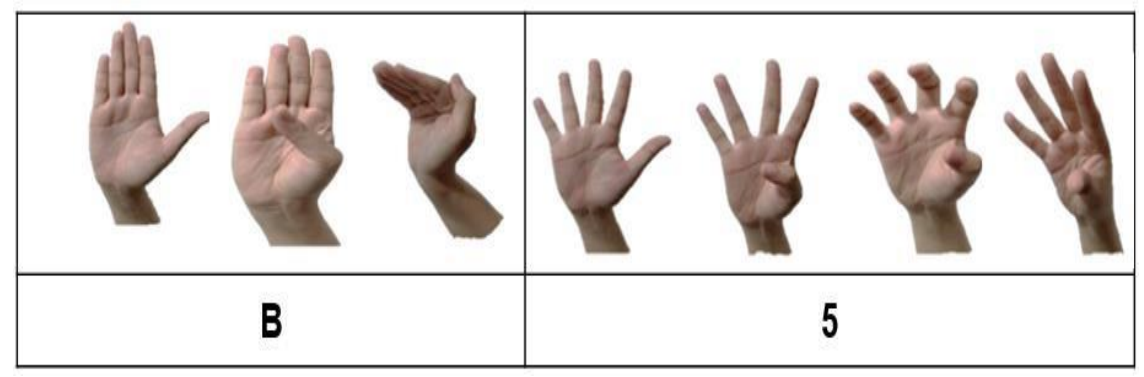

Fonte: Elaborada pelos autores

\subsection{Sistema de notação da configuração de mão de Liddell e Johnson (1989)}

Liddell e Johnson (1989), como parte de seu modelo de análise fonético-fonológica da ASL, propõem uma análise mais detalhada da CM. Em seu sistema, os autores analisam esse parâmetro com base em três conjuntos de traços articulatórios, representados como mostra a figura 2.

Figura 2. Descrição da CM de acordo com o sistema do Liddell e Johnson (1989)

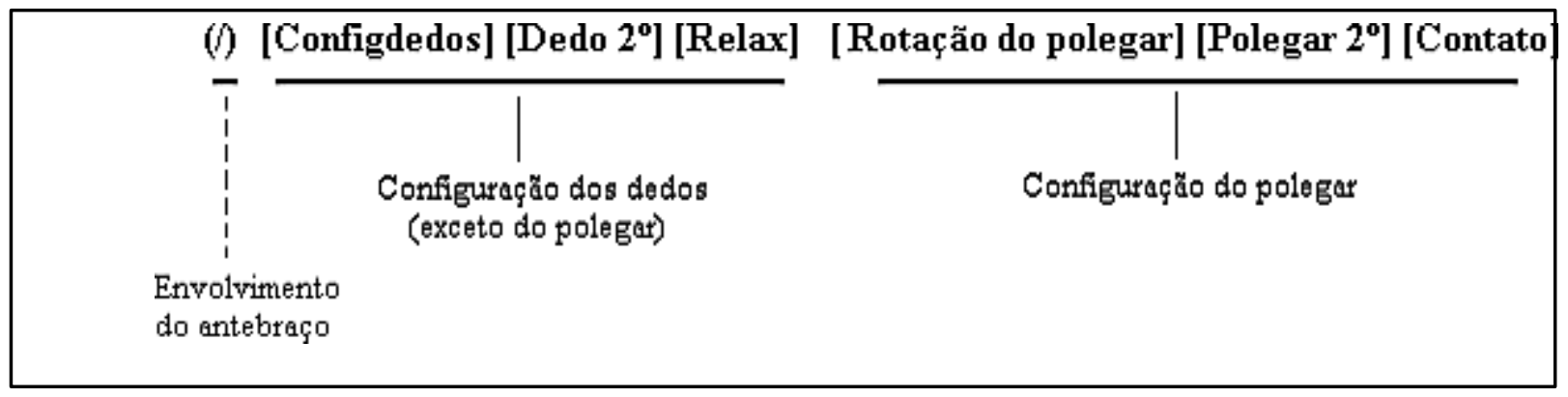

Fonte: Reproduzida de Xavier (2006, p. 54)

O primeiro traço (/) indica se o antebraço está envolvido na realização da CM. Caso esteja, usase o símbolo (/). Caso não esteja, ele não é incluído em sua notação. O segundo conjunto de traços representa como os dedos indicador, médio, anelar e mínimo estão posicionados.

Esse conjunto, por sua vez, abrange três subconjuntos de traços: [Configdedos], [Dedo $2^{\circ}$ ] e [Relax]. [Configdedos] se refere à abertura, ao fechamento, à adução, aproximação lateral, e à abdução, afastamento lateral, dos dedos. Para indicar cada um desses estados, Liddell e Johnson propõem 25 
símbolos, listados e ilustrados no anexo 1 deste trabalho. [Dedo $2^{\circ}$ ] se refere a flexões nas juntas proximais, mediais ou distais, as quais são indicadas por dois traços: achatado $\left({ }^{\wedge}\right)$, se a flexão é na(s) junta(s) proximal(is), e em gancho ("), se a flexão é na(s) junta(s) medial(is) e distal(is).

O terceiro conjunto de traços descreve o polegar, especificando, através do subconjunto [Rotação do polegar], se este está não-oposto [u] $]^{\mathrm{ii}}$, ou seja, no mesmo plano dos demais dedos, quando abertos, ou oposto [o], em plano paralelo; através do subconjunto de traços [Polegar $2^{\circ}$ ], se ele está achatado $\left({ }^{\wedge}\right)$ ou em gancho (“) e; por meio do subconjnunto de traços [Contato], a parte do polegar que contacta outro(s) dedo(s) ${ }^{\mathrm{iii}}$. A título de exemplificação, a representação das configurações de interesse neste trabalho é feita, de acordo com a proposta de Liddell e Johnson (1989), como mostra a figura 3.

Figura 3. CM em 'B' e '5' de acordo com o sistema do Liddell e Johnson (1989)

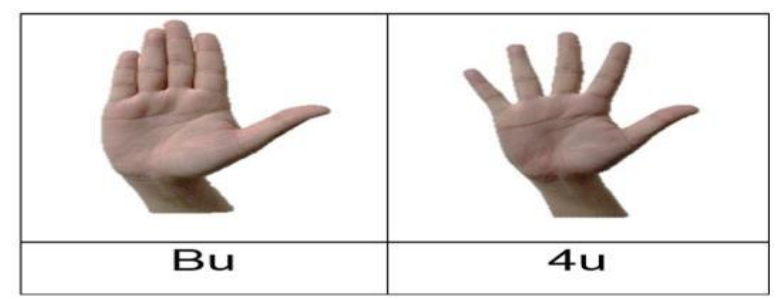

Fonte: Elaborada pelos autores

\subsection{Sistema de notação da configuração de mão de Johnson e Liddell $(2011,2012)$}

Johnson e Liddell $(2011,2012)$ propõem uma revisão de seu modelo anterior, principalmente, por conta da sua incapacidade de capturar detalhes articulatórios dos dedos indicador, médio, anelar e mínimo, até então descritos em conjunto através de 25 símbolos taxonômicos (cf. Anexo). No sistema mais recente, todos os aspectos de descrição perceptual global foram descartados e no lugar foram propostos descritores puramente articulatórios. Cada dedo é descrito separadamente, assumindo-se, assim, que eles são independentes uns dos outros e que não funcionam foneticamente como grupos de dedos selecionados e não selecionados.

A caracterização de cada dedo é feita com base em sua anatomia. Por conta disso, apesar de sua independência articulatória, os dedos indicador, médio, anelar e mínimo são tratados por Johnson e Liddell em bloco e separadamente do polegar por apresentarem estruturas diferentes. Conforme explicam os autores, diferentemente do polegar, tais dedos são compostos de três ossos, chamados de falanges proximal $(\mathrm{p})$, medial $(\mathrm{m})$ e distal $(\mathrm{d})$. A primeira ligada à segunda pela junta interfalângica distal (IFD) e a segunda à terceira pela junta interfalângica proximal (IFP). A falange proximal também 
se liga aos metacarpos (MC), ossos da palma da mão, pelas juntas metacarpofalângicas (MCF). As juntas IFD, IFP e MCF são responsáveis pelos diferentes graus extensão e flexão dos dedos. Adicionalmente, as juntas MCF são responsáveis pela abdução (separação lateral entre os dedos), adução (contato lateral entre os dedos) e hiperadução (cruzamento entre os dedos) (JOHNSON; LIDDELL, 2011).

O polegar, por sua vez, é formado por duas falanges: a distal (d) e a proximal (p). A primeira é ligada à segunda pela junta interfalângica distal (IFD) e a segunda, liga-se ao metacarpo (MC) pela junta metacarpofalângica (MCF). Essa última, por sua vez, é ligada aos ossos carpais pela junta carpometacarpal (CMC). Assim como no caso dos outros dedos, as juntas CMC e MCF também são responsáveis pelos diferentes graus de flexão e extensão do polegar. A junta CMC, por sua vez, por apresentar grande flexibilidade, permite ao polegar, além de aduzir-se e abduzir-se dos demais dedos, rotacionar-se, ou seja, mover-se sobre mais de um plano e contactar a superfície de fricção de outros dedos (JOHNSON; LIDDELL, 2012).

A Figura 4 sintetiza todas essas informações anatômicas sobre a mão. Observe-se que são utilizados os números 1, 2, 3 e 4 para designar os dedos indicador, médio, anelar e mínimo, respectivamente, e o símbolo $\varnothing$ para o polegar.

Figura 4. Ossos e juntas da mão

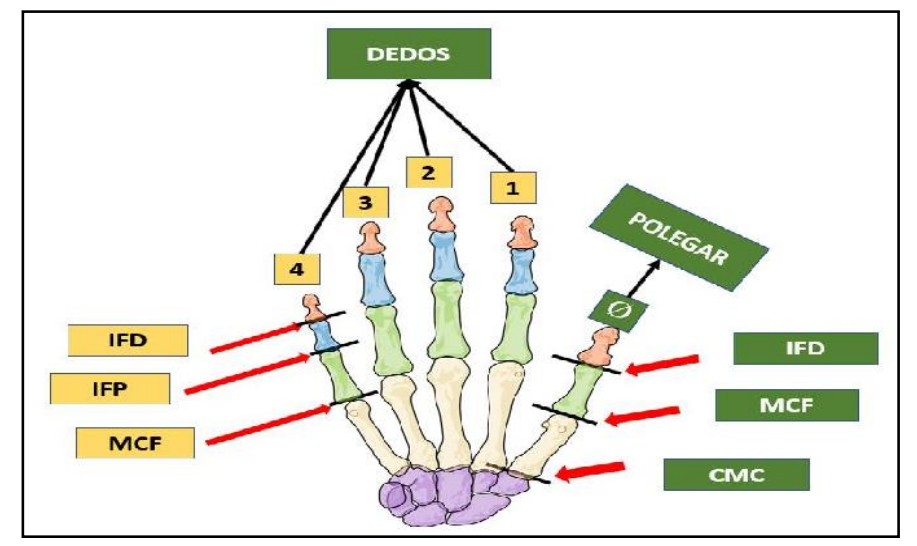

Fonte: https://pt.pngtree.com/element/down?id=MjgxMTE1NA==\&type=1

Com base nisso, na versão de 2011/2012 de seu sistema de notação da CM, Johnson e Liddell propõem que a descrição completa desse parâmetro necessita de todas as especificações incluídas no esquema mostrado na Figura 5. 
Figura 5. Esquema completo para notação da configuração de mão no sistema Johnson e Liddell $(2011,2012)$

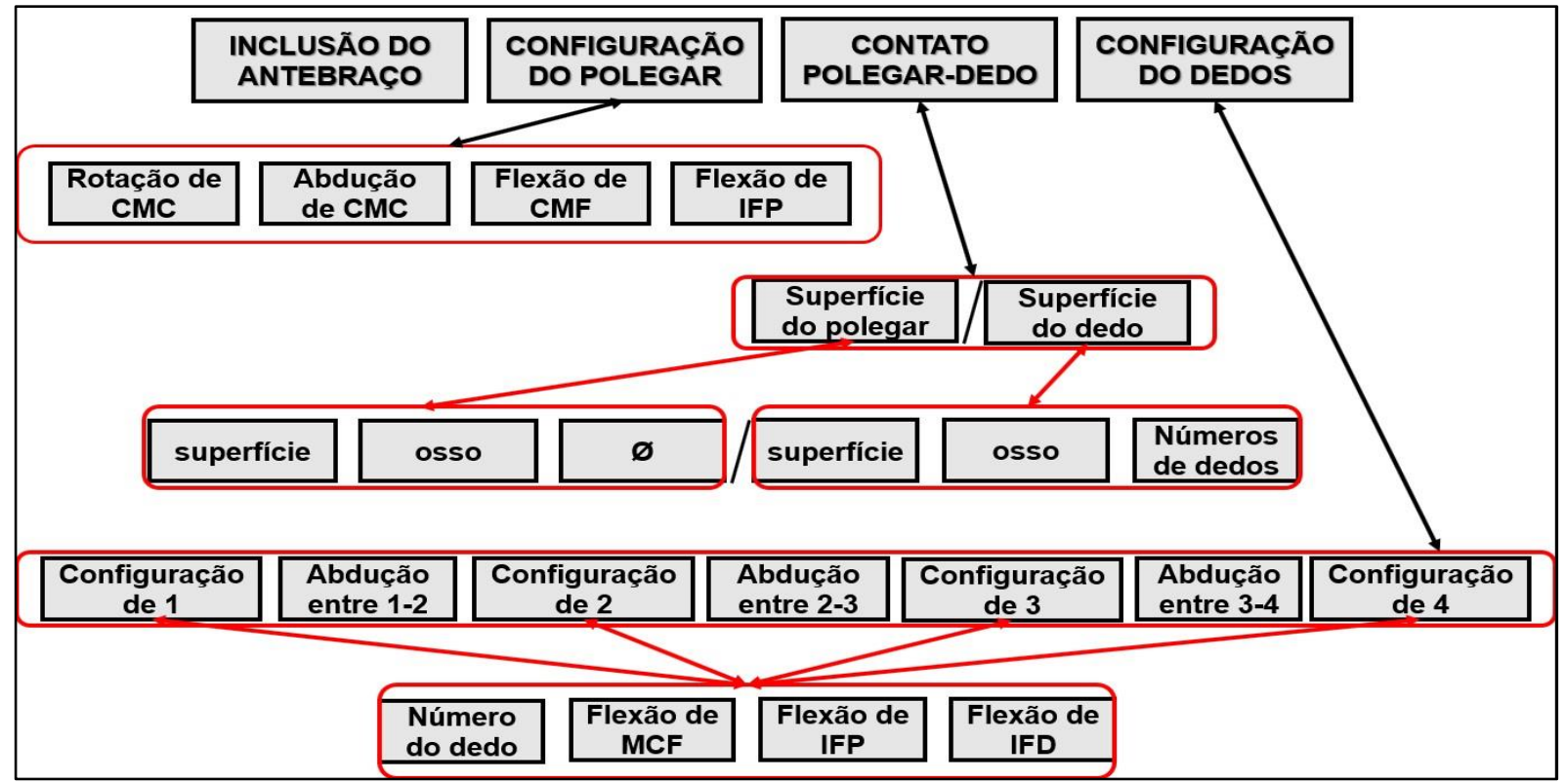

Fonte: Traduzida e adaptada de Johnson e Liddell (2012, p.332).

Da esquerda para a direita, o primeiro traço a ser registrado em relação a uma $\mathrm{CM}$ é a participação do antebraço. Havendo participação, utiliza-se o símbolo $(\sqrt{ })$. Na sequência, deve-se especificar a configuração do polegar, a qual abrange quatro subespecificações: a rotação da junta carpometacarpal (CMC), o seu grau de abdução e o grau de distensão e flexão das suas juntas metacarpofalângica (MCF) e interfalângica proximal (IFP). Em outras palavras, determina-se, respectivamente, se o polegar está oposto (O), ou seja, em plano paralelo aos outros dedos, não-oposto ou neutro (U) ou ao lado dos demais dedos (L); se ele está abduzido ( $く$ ), aduzido (=) ou neutro (<), se as juntas MCF e IFP estão completamente hiperestendidas (H), parcialmente hiperestendidas (h), completamente estendidas (E), parcialmente estendidas (e), parcialmente flexionadas (f) ou completamente flexionadas (F), como ilustram as imagens na Figura 6.

Figura 6. Graus de extensão e flexão do polegar e seus respectivos símbolos

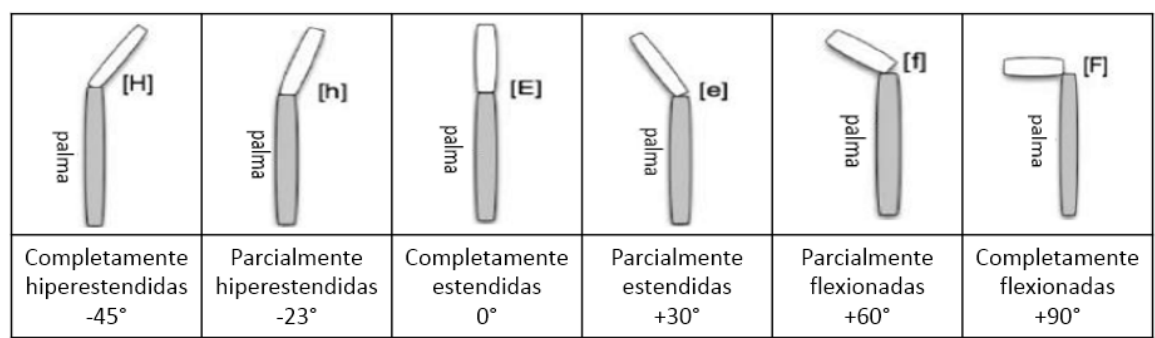

Fonte: Traduzida e reproduzida de Johnson e Liddell (2011, p.27) 
Na presença de contato entre o polegar e outro(s) dedo(s), deve-se especificar quais superfícies, de ambos, estão se contactando. Essa especificação é feita por meio da designação da superfície e do osso, indicados na Figura 7.

Figura 7. Superfícies e ossos do polegar e de outros dedos

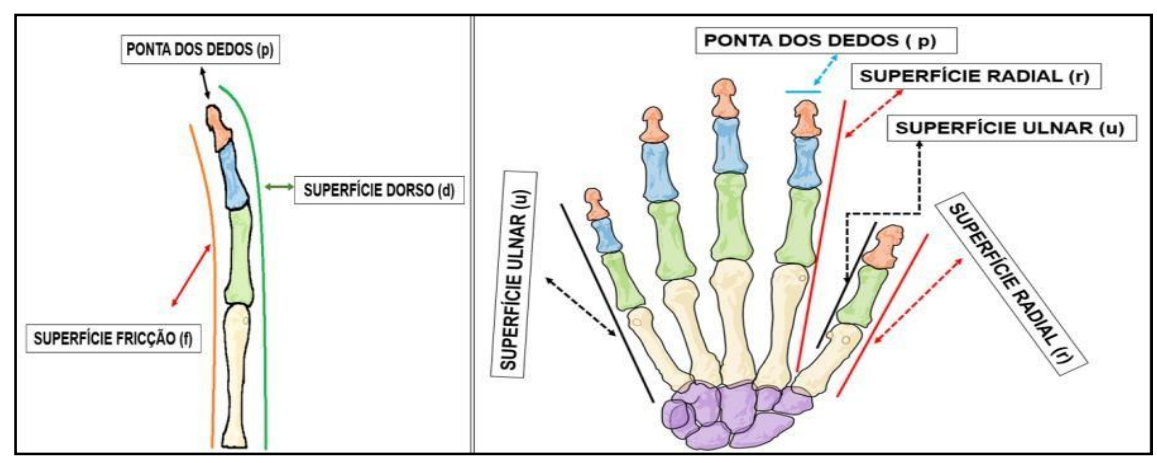

Fonte: https://pt.pngtree.com/element/down?id=MjgxMTE1NA==\&type=1

Finalmente, deve-se descrever a configuração dos demais dedos. Na verdade, deve-se especificar o grau de extensão e flexão de cada junta, MCF, IFP e IFD, de cada dedo, 1, 2, 3 e 4, usando os mesmos símbolos apresentados na Figura 6. Entre as descrições de cada dedo, deve-se também determinar o grau de abdução entre eles, utilizando-se os mesmos símbolos empregados na caracterização do polegar.

De acordo com o sistema de Johnson e Liddell (2011, 2012), as CM em B e em 5 aqui analisadas são representadas tal como mostra a figura 8.

Figura 8. Representação das CM em B (a) e 5 (b).

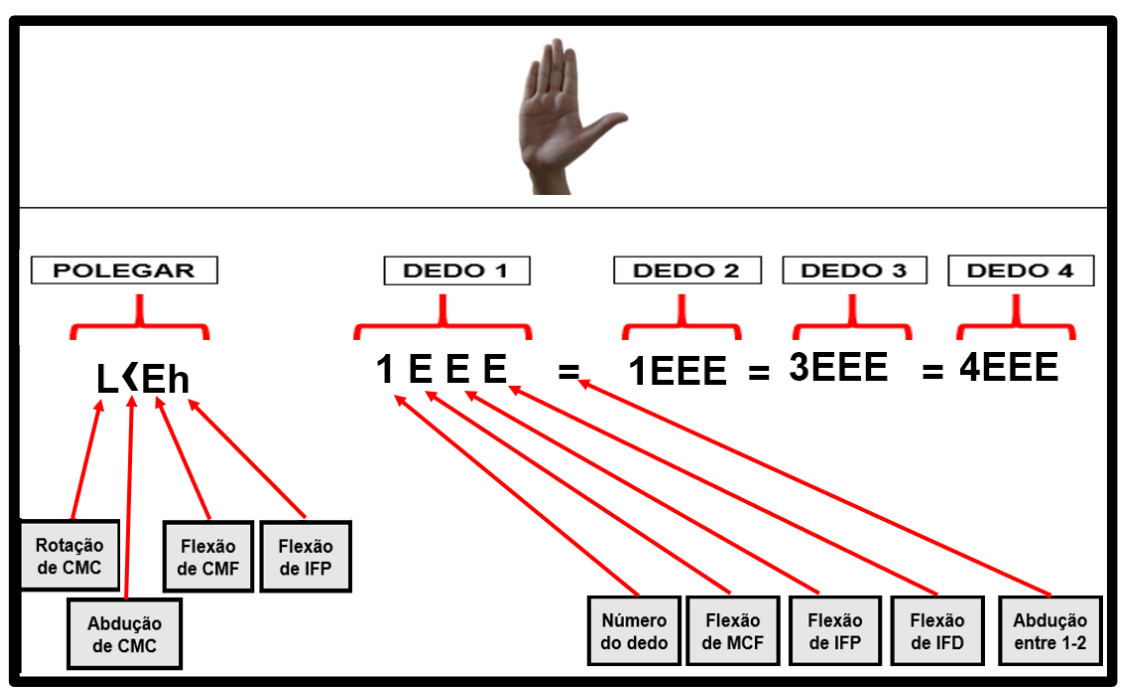

(a) 


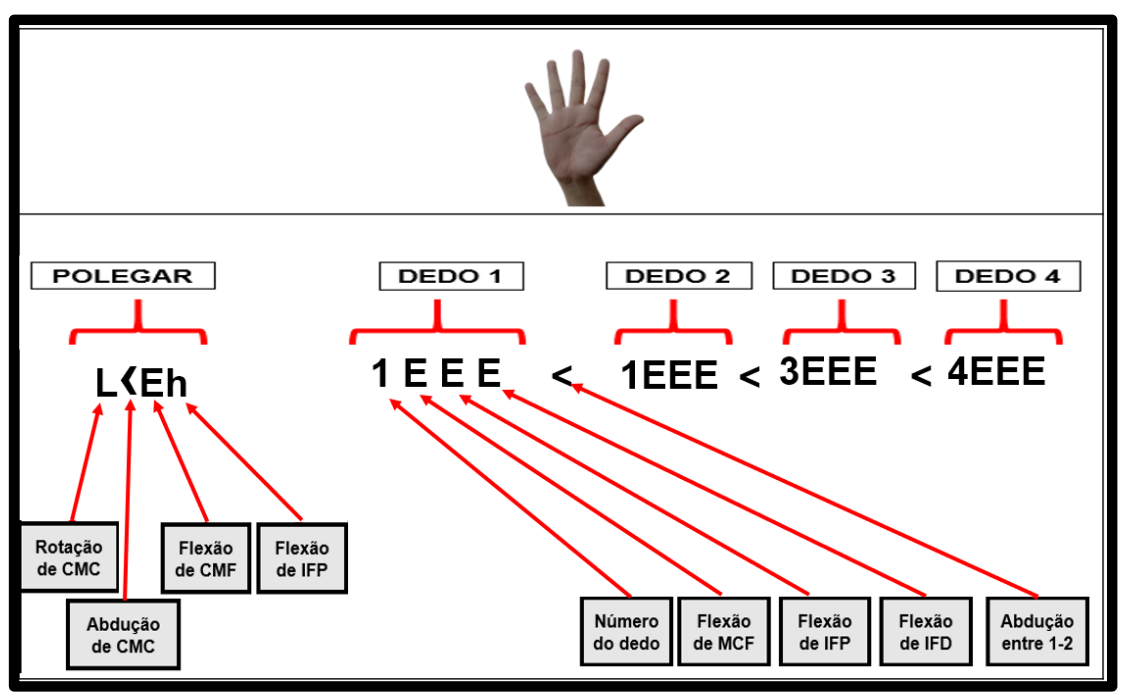

(b)

Fonte: Elaborada pelos autores

Por meio da comparação desses três sistemas de notação do parâmetro CM, embasada em dados da libras, objetiva-se demonstrar que o mais recente deles, ou seja, o de Johnson e Liddell $(2011,2012)$ é o mais apropriado para a análise fonética das línguas sinalizadas, dada sua alta capacidade descritiva.

\section{Metodologia}

Foram selecionados 26 dos 60 sinais originalmente coletados por Xavier e Barbosa (2014) de 12 sujeitos surdos (seis homens e seis mulheres) da cidade de São Paulo. A seleção desses sinais se baseou na presença da CM 'B', mão aberta com dedos unidos lateralmente, ou '5', mão aberta com dedos espalmados, em pelo menos uma das três produções dos 12 sujeitos surdos que participaram do referido estudo.

Para efeitos de apresentação, os 26 sinais selecionados para este estudo foram agrupados em três categorias, a saber, monomanuais, bimanuais equilibrados, ou seja, com movimento em ambas as mãos, e bimanuais não-equilibrados, isto é, realizados com uma mão ativa e outra passiva (Figura 9) (Xavier, 2014). Os sinais bimanuais não-equilibrados, por sua vez, foram subcategorizados como simétricos (com a mesma configuração em ambas as mãos) e assimétricos (com mãos configuradas diferentemente). 
Figura 9. Sinais selecionados, agrupados por tipo: monomanual, bimanual equilibrado e bimanual nãoequilibrado: simétrico e assimétrico

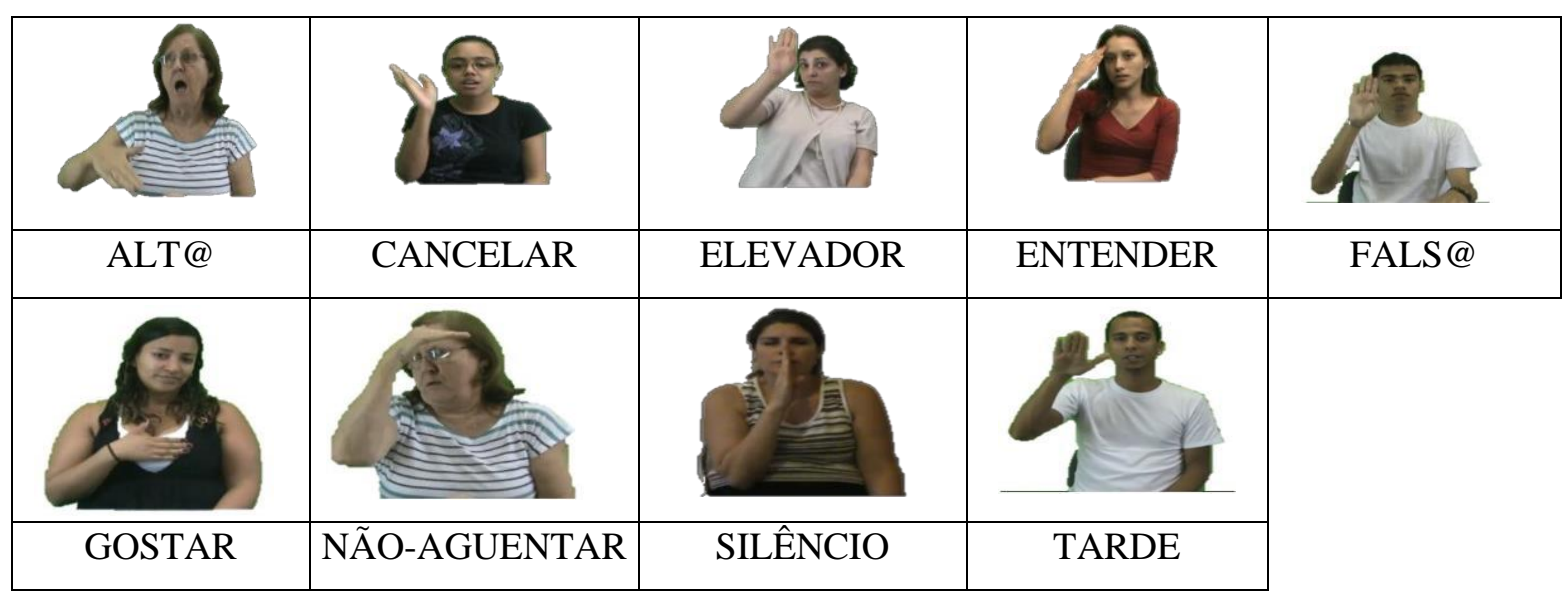

Sinais monomanuais

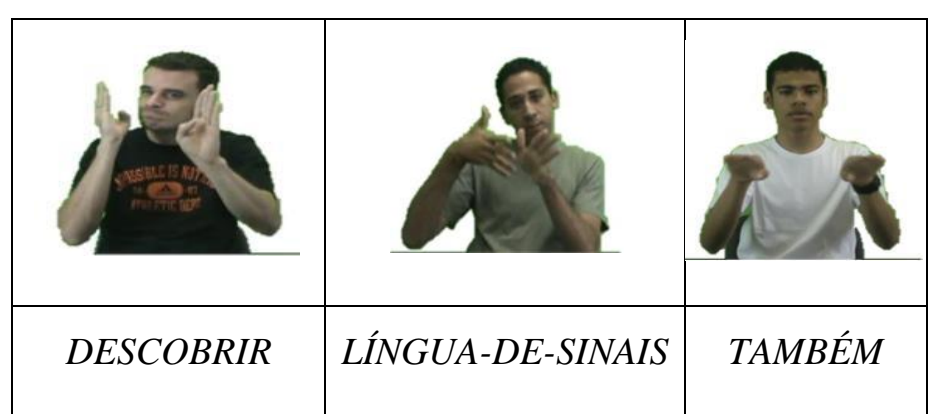

Sinais bimanuais equilibrados

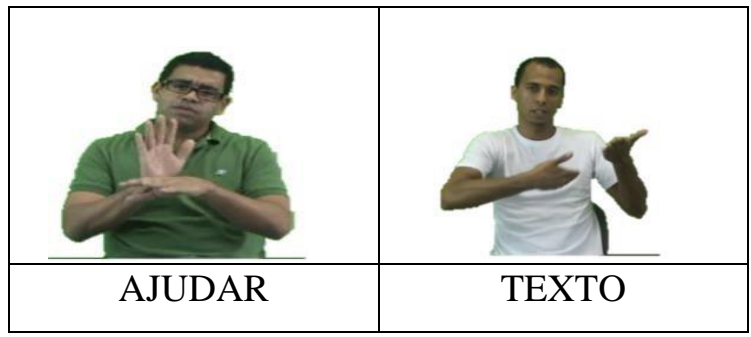

Sinais bimanuais não-equilibrados simétricos 


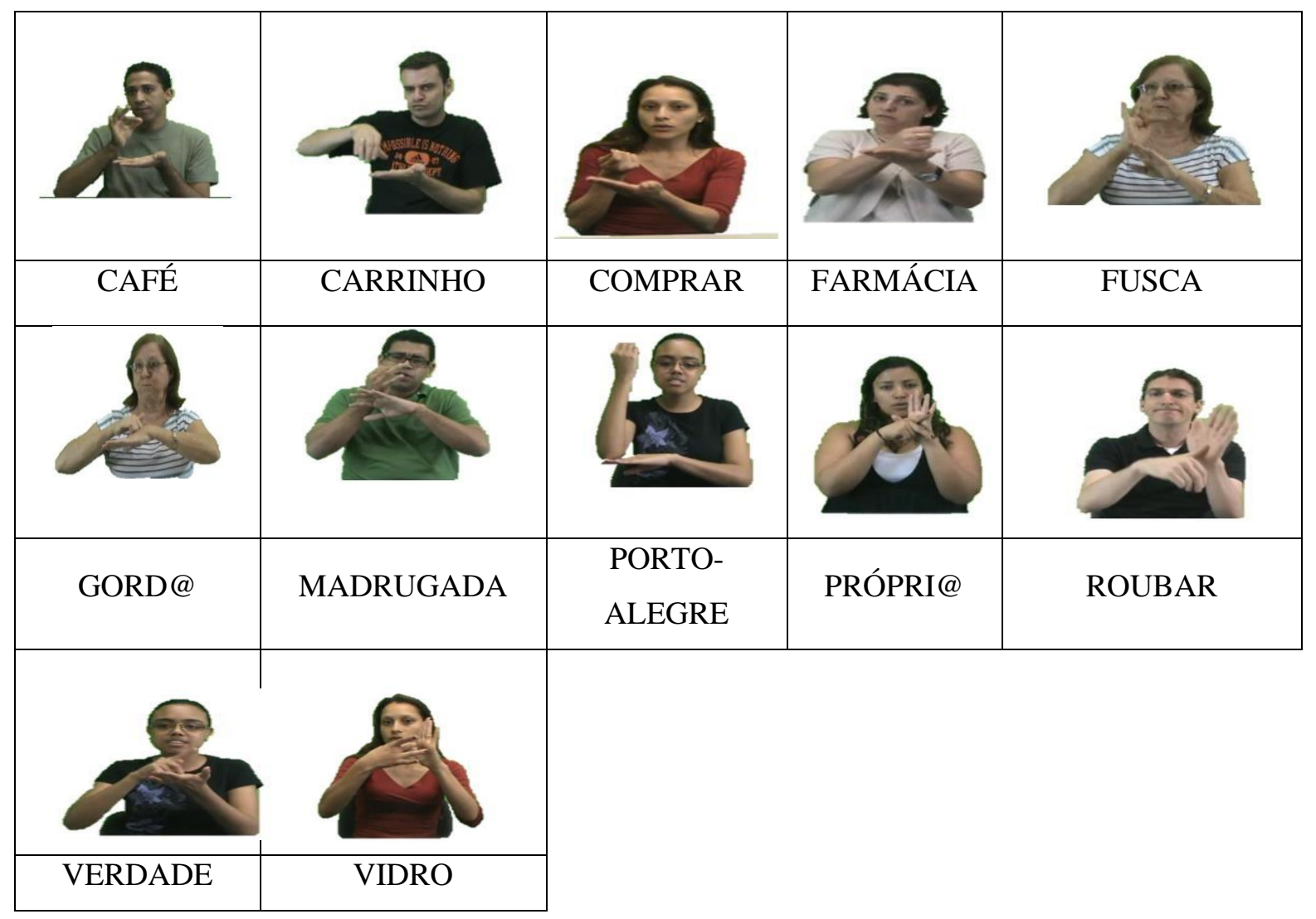

Sinais bimanuais não-equilibrados assimétricos

Fonte: Elaborada pelos autores

A seleção dessas duas CM, por sua vez, se fundamentou no fato de ambas fazerem parte do conjunto de sete configurações consideradas translinguisticamente básicas, tanto por razões articulatórias, quanto por razões perceptuais (BATTISON, 1978). Essa seleção, em detrimento de outras, também se justifica por este trabalho ser um desdobramento de trabalhos sobre a realização concreta de outras CM básicas, a saber, '1'/'D', 'A' e 'S' e por elas, assim como nos demais casos, variarem entre si (ALECRIM; XAVIER, 2017, a sair).

A análise dos dados em discussão foi realizada através do software livre Eudico Language Annotator $(\text { Elan })^{\mathrm{iv}}$, que permitiu anotar, sincronizadamente aos vídeos, as configurações de mão de cada sinal, usando cada um dos três sistemas acima descritos, como mostra a figura 10. 
Figura 10. Print da tela do Elan: configuração de um dos sinais analisados nos três sistemas em discussão

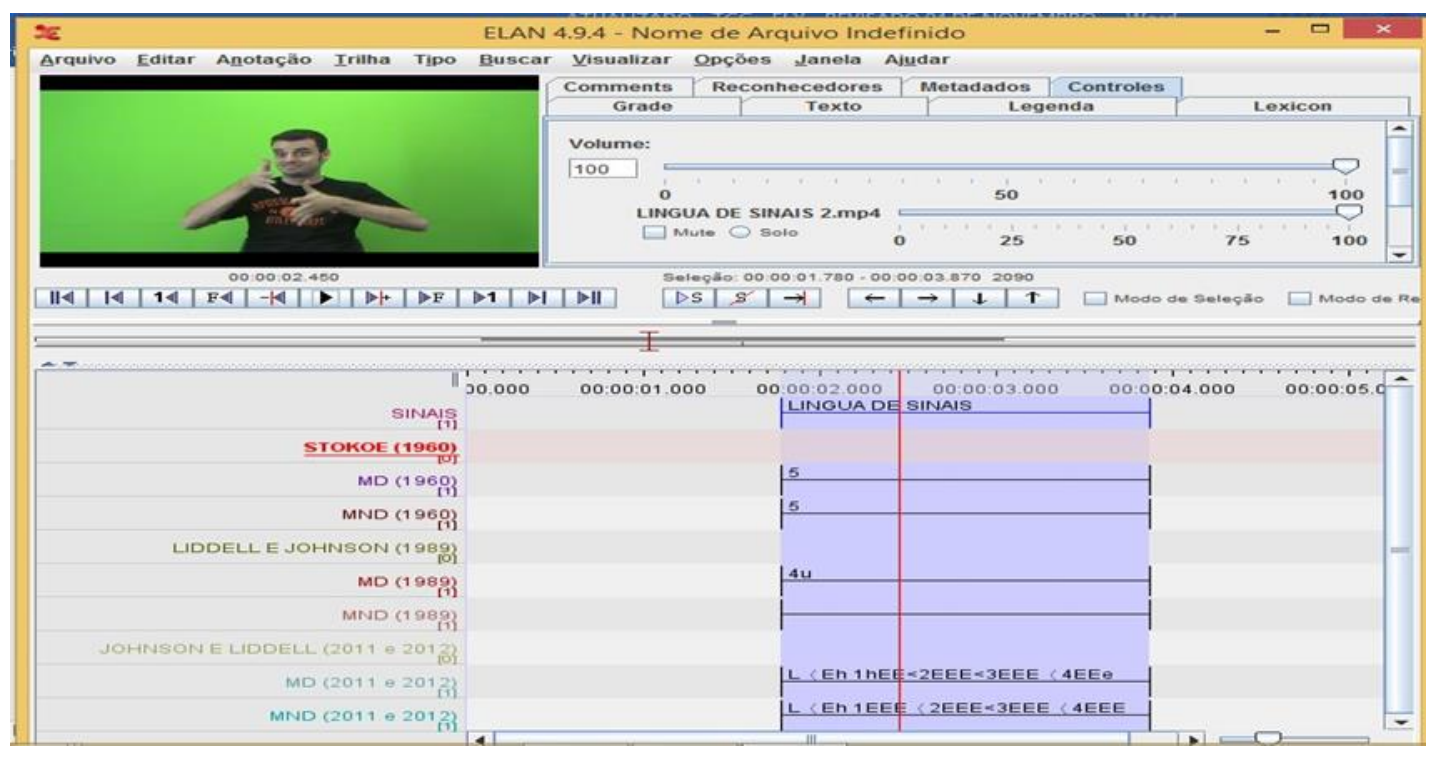

Fonte: Elaborada pelos autores

\section{Resultados}

Algumas realizações dos 26 sinais selecionados para este trabalho tiveram de ser excluídas, pois os sinalizantes empregaram CM diferentes daquelas que, seguindo a proposta de Stokoe (1960), são referidas como 'B' e '5'. Consequentemente, de 312 dados (26 sinais x 12 sujeitos), foram analisados 185. Como mostra a figura 11, dentre estes, predominam produções envolvendo a CM 'B'.

Figura 11. Frequência das CM 'B' e '5'

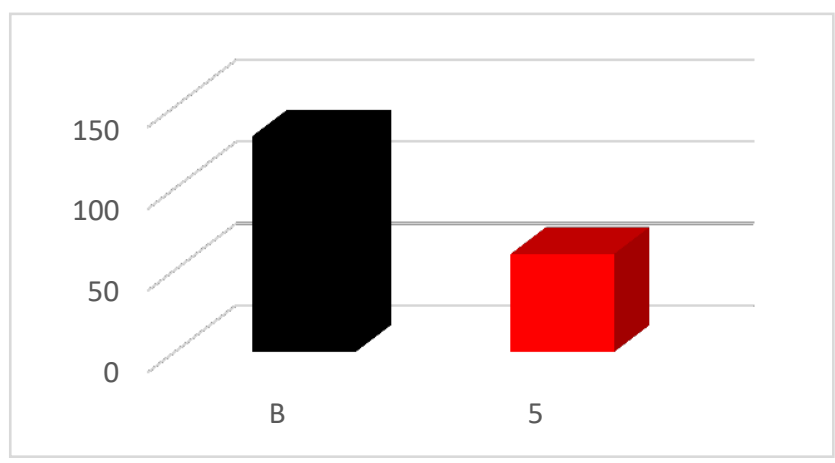

Fonte: Elaborada pelos autores 
Separando essas frequências por sujeitos, observa-se, como mostra a figura 12, que, com exceção dos sujeitos 3 e 4, todos os outros empregaram mais a CM em 'B' do que da CM em '5'.

Figura 12. Frequência das CM 'B' e ' 5 ' por sujeito

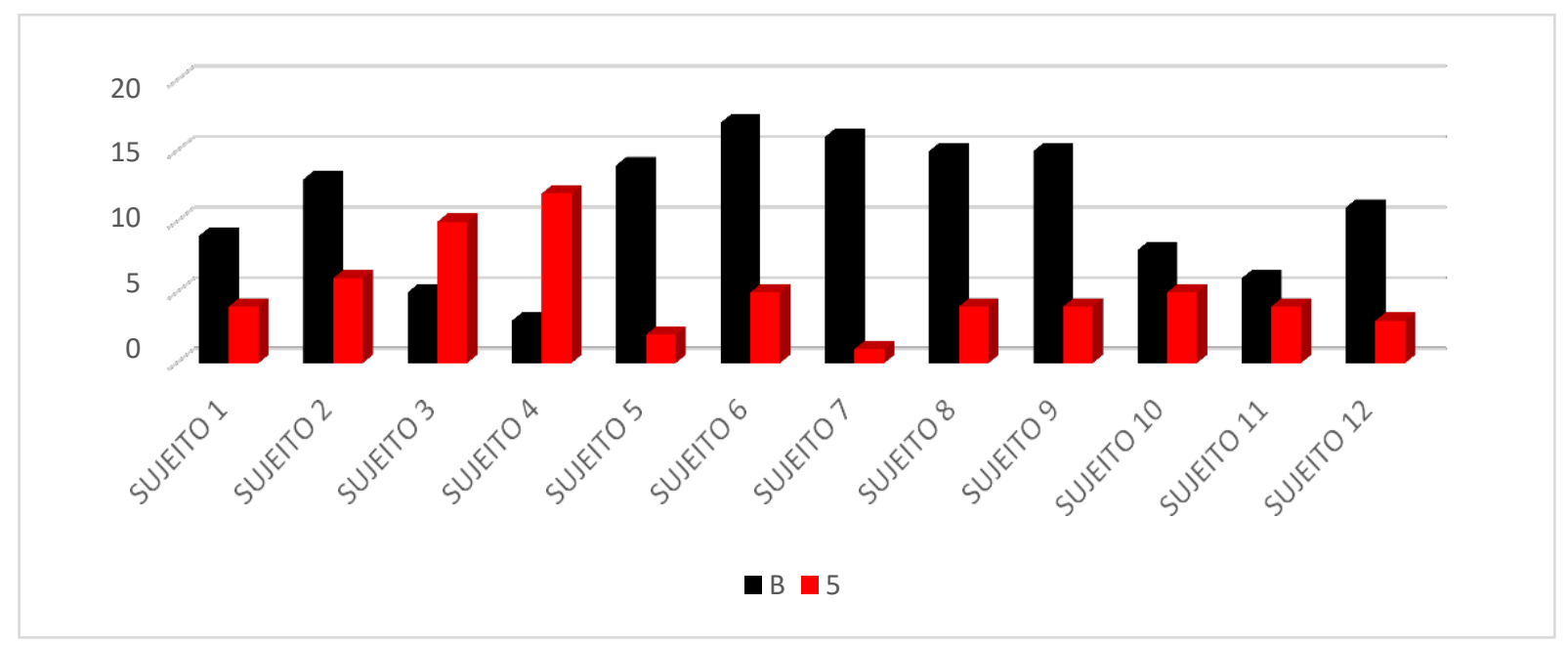

Fonte: Elaborada pelos autores

Dividindo essas mesmas frequências por sinal, como mostra a figura 13, vê-se que (1) ambas as $\mathrm{CM}$ são atestadas na realização de todos os sinais, mas que (2) a CM 'B' é a mais frequente em todos os casos, com exceção aos sinais LÍNGUA-DE-SINAIS e ROUBAR, em que a CM '5' foi a mais frequentemente empregada.

Figura 13. Frequência das $C M$ ' $B$ ' e ' 5 ' por sinal

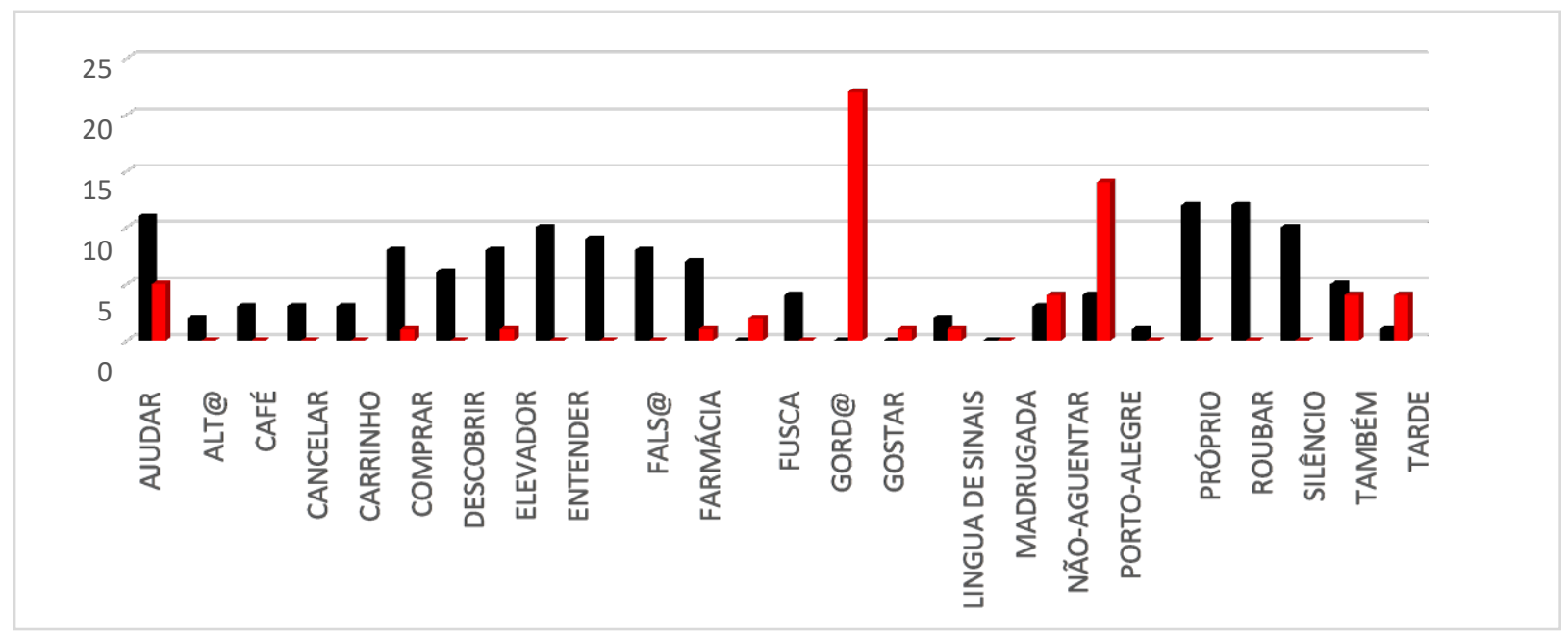

Fonte: Elaborada pelos autores 
Uma análise mais acurada desses mesmos dados revelou que as duas configurações em questão exibiram variação no polegar, fato que não pôde ser capturado pelo sistema de Stokoe (1960). Por essa razão, todas as produções aqui consideradas foram também anotadas por meio do sistema de notação da CM de Liddell e Johnson (1989). Com isso, foi possível identificar duas variantes para a CM '5' e seis variantes para a CM 'B'. Seguindo Liddell e Johnson (1989), as variantes de 'B' podem ser representadas como 'B(?)', 'Bo', 'Bo', 'Bo^', 'Bu', 'Bu-' e 'Bu${ }^{\wedge}$, e as de '5' como '4o' e ‘4u' (Figura 14).

Figura 14. Variantes da CM ‘4' e 'B' representadas segundo sistema Liddell e Johnson (1989)

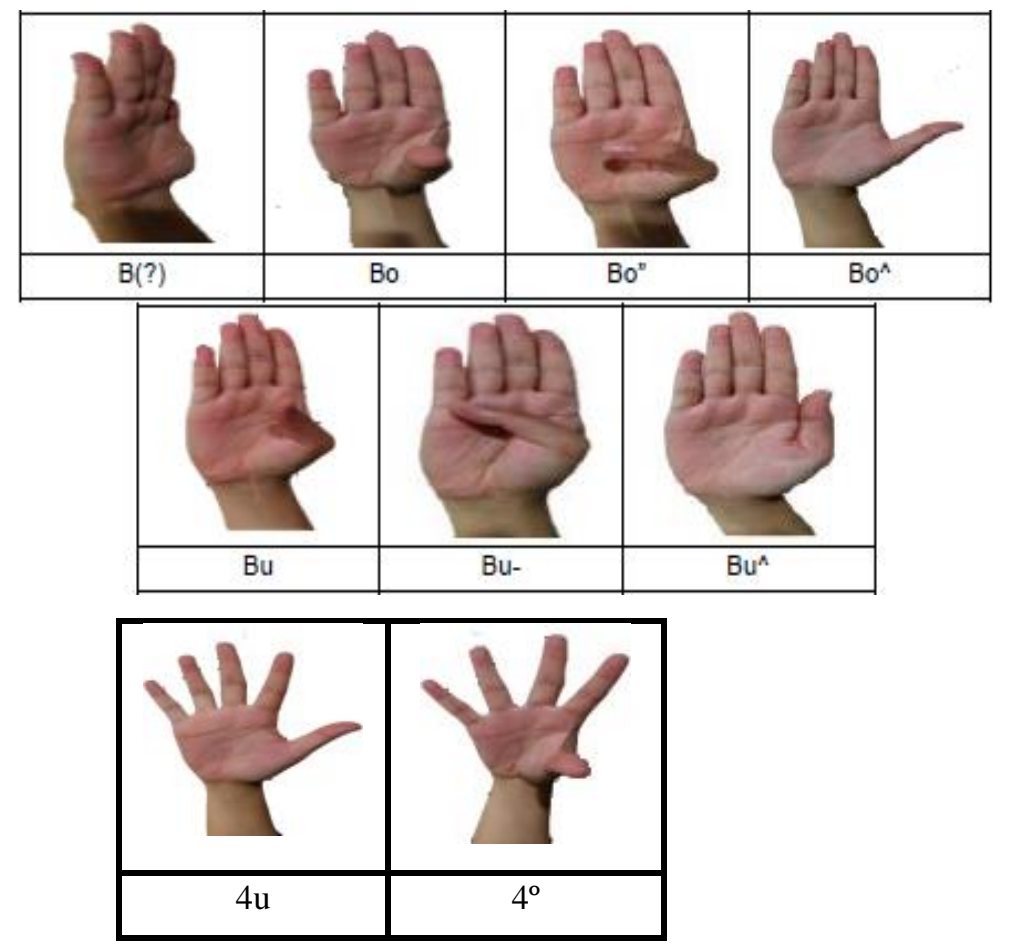

Fonte: Elaborada pelos autores

Uma vez identificadas as variantes das CM 'B' e '5', diferenciadas pelas posições distintas do polegar, foi possível observar, como mostra a figura 15, sua frequência no conjunto de dados considerados e destacar ' $4 u$ ' e 'Bu' como as mais utilizadas. Cabe mencionar, no entanto, que em $20 \%$ dos dados não foi possível determinar a posição do polegar, por conta da orientação da mão em relação à câmera no momento da coleta dos dados por Xavier e Barbosa (2014). Esses casos foram indicados no gráfico abaixo por meio da interrogação. 
Figura 15. Variantes das CM 'B' e ' 5 ' representadas segundo sistema Liddell e Johnson (1989)

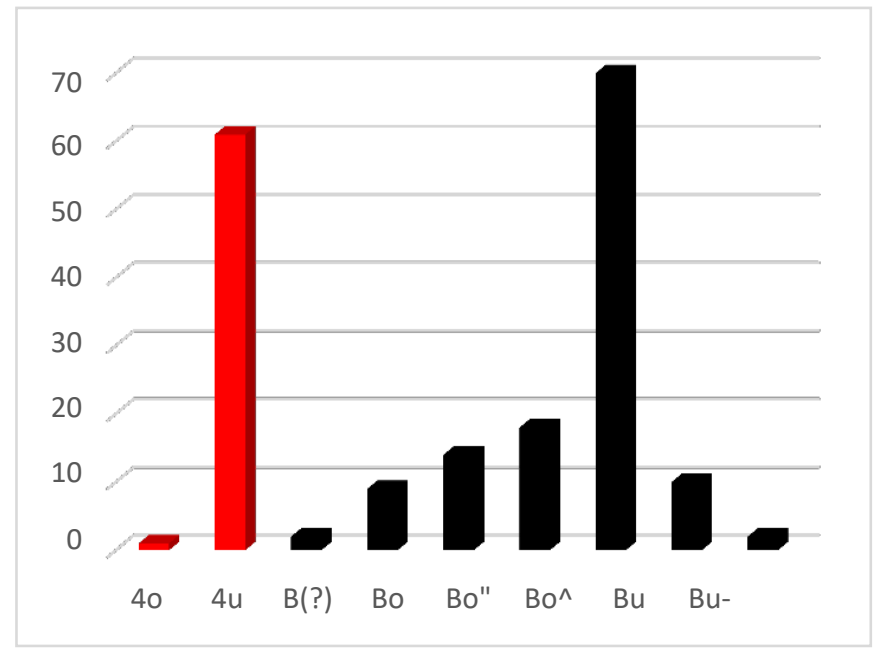

Fonte: Elaborada pelos autores

Separando as frequências das CM de interesse por sujeitos, observa-se mais uma vez que, como mostra a Figura 16, com exceção dos sujeitos 3 e 4, para quem predomina a variante ' $4 u$ ' da CM '5', variantes da CM 'B' são predominantes, sendo a variante Bu a mais frequente.

Figura 16. Variantes das CM 'B' e ' 5 ' representadas de acordo com o sistema de Liddell e Johnson separadas por sujeito

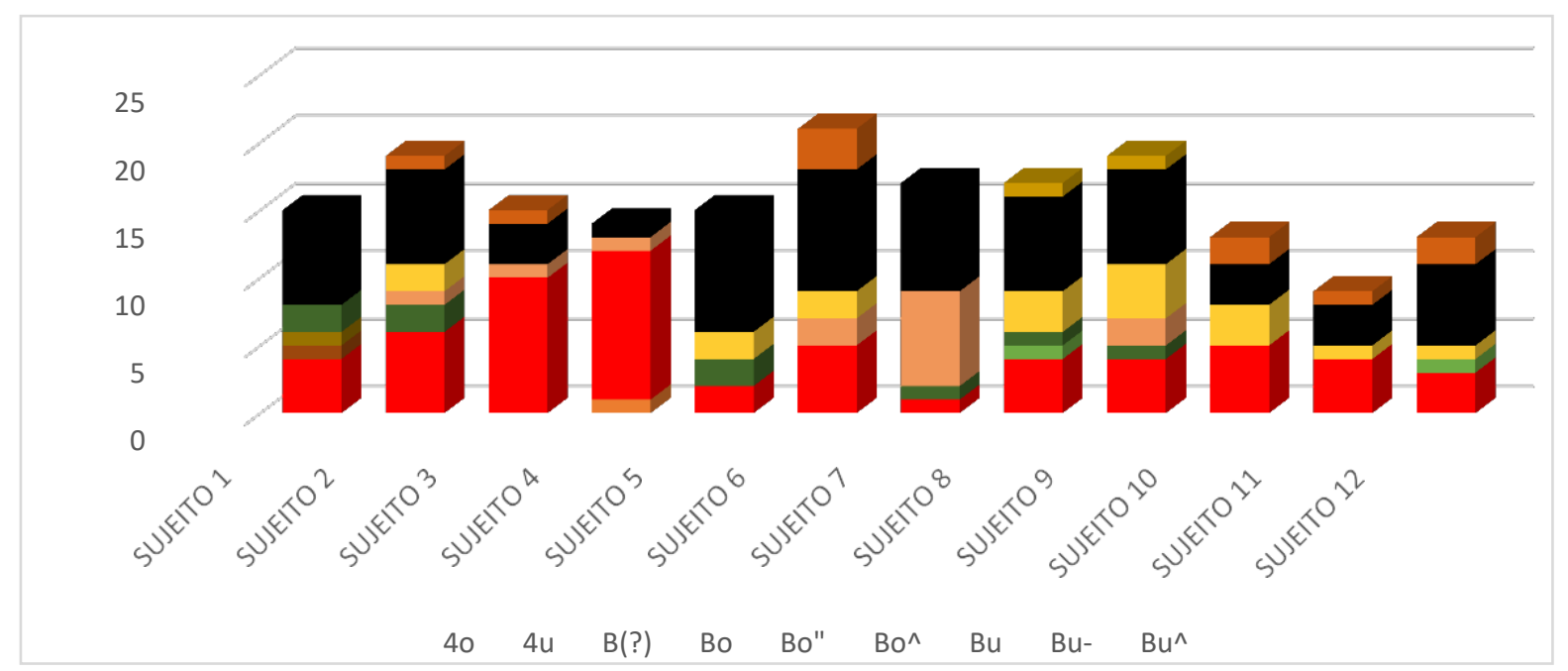

Fonte: Elaborada pelos autores

Dividindo, agora, as variantes das CM em análise por sinal, pode-se ver a variabilidade na realização desses sinais. Em AJUDAR, por exemplo, todas as variantes de 'B' e de '5' foram atestadas 
(Figura 17). Nota-se, no entanto, variação em relação a isso, já que, em alguns sinais, a diversidade de CM parece ser menor (cf. TARDE).

Figura 17 . Variantes das CM 'B' e '5' representadas de acordo com o sistema de Liddell e Johnson separadas por sinal

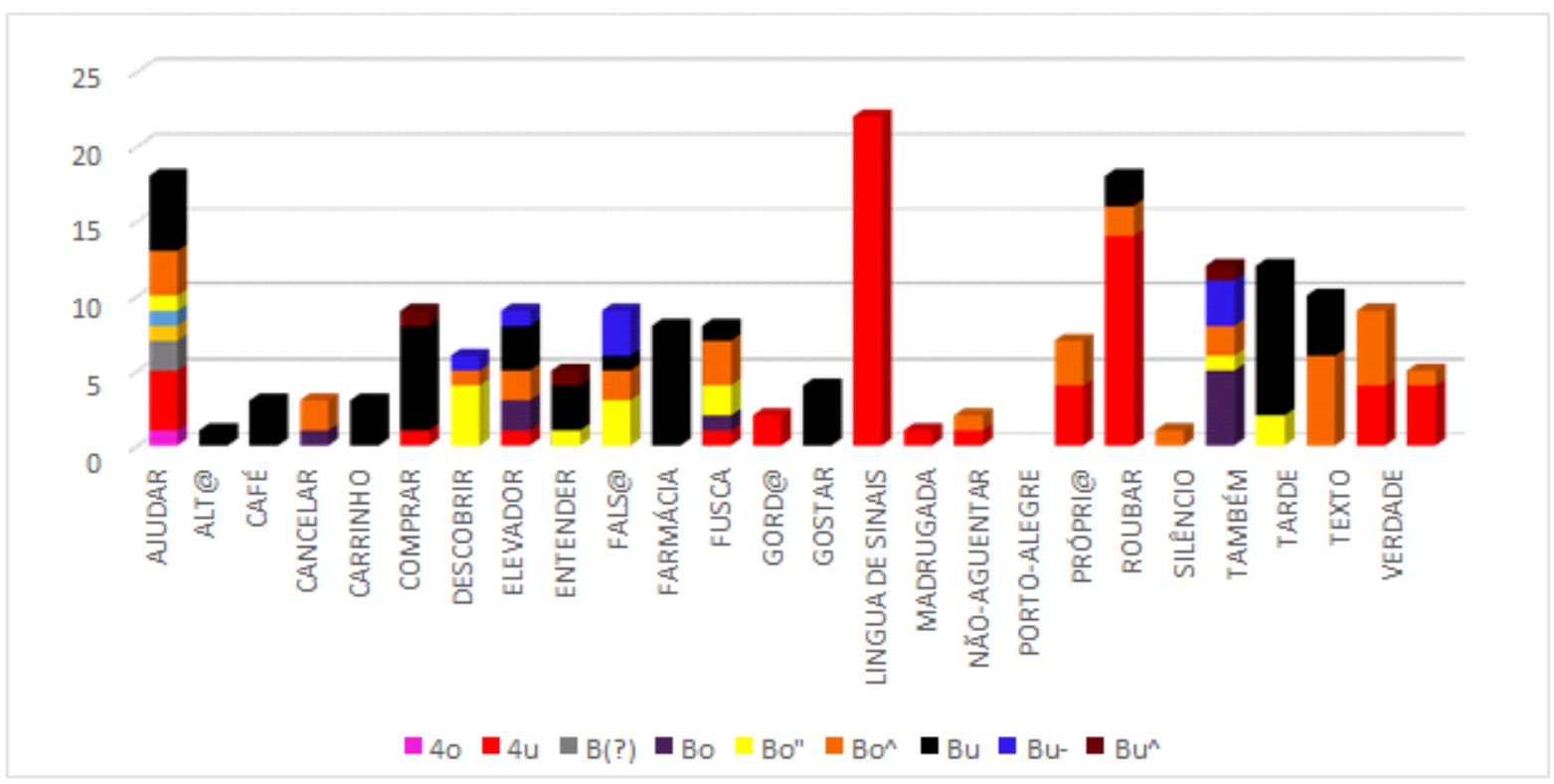

Fonte: Elaborada pelos autores

Embora o sistema de Liddell e Johnson (1989) represente um avanço em relação ao de Stokoe (1960), por ser capaz de capturar a variação no polegar, ele tem limitações. Entre as principais está a impossibilidade de registrar a variação que ocorre nos dedos indicador, médio, anelar e mínimo durante a articulação dos sinais. Como visto, a solução proposta por Johnson e Liddell (2011, 2012) consiste justamente na descrição de cada junta de cada dedo separadamente, bem como no seu grau de adução em relação ao dedo adjacente.

Para ilustrar a capacidade do novo sistema em dar conta dessa variação, elegeram-se, dentre os sinais analisados, LÍNGUA-DE-SINAIS e TARDE. A escolha desses sinais se deveu ao fato de que eles apresentam, respectivamente, a variante mais frequente das $\mathrm{CM}$ '5', a saber, ' $4 \mathrm{u}$ ', e 'B', a saber, 'Bu'. Conforme indicam as figuras 18 e 19, observa-se variação intersujeito nas diferentes juntas de cada dedo, incluindo o polegar, bem como nos diferentes graus de adução entre eles. 
Figura 18. Notação da CM do sinal LÍNGUA-DE-SINAIS na produção de cada sujeito, de acordo com o sistema de Johnson e Liddell (2011, 2012). MD: mão dominante e MND: mão não-dominante

\begin{tabular}{|c|c|c|c|c|}
\hline & & & \multicolumn{2}{|c|}{ POLEGAR } \\
\hline & LIUIO & \langle|\langle\rangle$=$ & MCF & IFD \\
\hline SUJEITO 1 & U & $<$ & $E$ & $\mathrm{~h}$ \\
\hline SUJEITO 2 & $\mathrm{L}$ & 2 & $E$ & $h$ \\
\hline SUJEITO 3 & $\mathrm{L}$ & i & $E$ & e \\
\hline SUJEITO 4 & $\bar{L}$ & 1 & $E$ & $\mathrm{~h}$ \\
\hline SUJEITO5 & $\bar{L}$ & $\frac{i}{<}$ & $E$ & $\mathrm{~h}$ \\
\hline SUJEITO 6 & $\mathrm{L}$ & $<$ & $E$ & $\mathrm{~h}$ \\
\hline \multicolumn{5}{|l|}{ SUJEITO 7} \\
\hline SUJEITO 8 & L & 《 & $E$ & h \\
\hline SUJEITO9 & $\bar{L}$ & $<$ & $E$ & $h$ \\
\hline SUJEITO 10 & $\bar{U}$ & $<$ & $E$ & $h$ \\
\hline SUJEITO 11 & U & $<$ & e & $\mathrm{h}$ \\
\hline SUJEITO 12 & L & 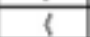 & $\bar{E}$ & $\mathrm{~h}$ \\
\hline
\end{tabular}

\begin{tabular}{|c|c|c|c|c|c|c|c|c|c|c|c|c|c|c|}
\hline \multicolumn{15}{|c|}{ LINGUA DE SINAIS (MD) } \\
\hline \multicolumn{3}{|c|}{1} & \multicolumn{4}{|c|}{2} & & \multicolumn{3}{|c|}{3} & & \multicolumn{3}{|c|}{4} \\
\hline IFD & IFP & MCF & $\langle 1<1=$ & IFD & IFP & MCF & $\{1<1=$ & IFD & IFP & MCF & $\langle 1<1=$ & IFD & IFF & MCF \\
\hline$E$ & $\mathrm{E}$ & $E$ & 1 & $E$ & $E$ & $E$ & $<$ & $E$ & $E$ & $E$ & 1 & $\mathrm{E}$ & $E$ & 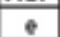 \\
\hline$E$ & $E$ & $E$ & i & $E$ & $E$ & $E$ & $<$ & $\mathrm{E}$ & $E$ & $E$ & l & $E$ & $E$ & $E$ \\
\hline$E$ & e & $\bar{E}$ & i & $\bar{E}$ & $E$ & $E$ & 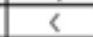 & $E$ & $E$ & $\bar{E}$ & i & $E$ & $E$ & $e$ \\
\hline$E$ & $E$ & $\bar{E}$ & $<$ & $E$ & $\bar{E}$ & $E$ & 2 & $E$ & $E$ & $E$ & $<$ & $E$ & $E$ & $e$ \\
\hline$E$ & $E$ & $E$ & 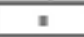 & $E$ & $\bar{E}$ & $h$ & < & $E$ & $E$ & $E$ & 2 & $E$ & $E$ & 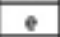 \\
\hline$h$ & $E$ & $E$ & 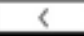 & $E$ & $E$ & $E$ & 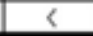 & $E$ & $E$ & $\mathrm{E}$ & $<$ & $E$ & $E$ & $e$ \\
\hline$E$ & $E$ & $E$ & $<$ & $E$ & $E$ & $t$ & 8 & $E$ & $E$ & $t$ & & 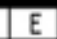 & $\mathrm{E}$ & \\
\hline$E$ & $E$ & $\mathrm{~h}$ & $<$ & $E$ & $\bar{E}$ & $h$ & $\frac{1}{2}$ & $\bar{E}$ & $E$ & $\mathrm{~h}$ & < & $E$ & $E$ & $h$ \\
\hline$E$ & $e$ & e & 8 & $E$ & $E$ & $E$ & 8 & $E$ & $E$ & $e$ & $\bar{k}$ & $e$ & $e$ & $e$ \\
\hline$E$ & $E$ & $E$ & $<$ & $E$ & $E$ & $E$ & $<$ & $E$ & E & $E$ & $<$ & 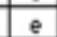 & e & \\
\hline$E$ & $\mathrm{E}$ & $E$ & 2 & $E$ & $E$ & $E$ & 2 & $E$ & $E$ & $e$ & 2 & $E$ & $E$ & \\
\hline
\end{tabular}

\begin{tabular}{|c|c|c|c|c|}
\hline & & & \multicolumn{2}{|c|}{ POLEGAR } \\
\hline & LIU10 & $\langle 1<1=$ & MCF & IFD \\
\hline SUJEITO 1 & $\mathrm{~L}$ & 1 & $E$ & $E$ \\
\hline SUJEITO 2 & $\bar{L}$ & i & $E$ & $h$ \\
\hline SUJEITO 3 & L & 1 & $E$ & $e$ \\
\hline SUJEITO 4 & L & 8 & $E$ & $\mathrm{~h}$ \\
\hline SUJEITO 5 & $\mathrm{~L}$ & द & $E$ & $\mathrm{~h}$ \\
\hline SUJEITO 6 & $\mathrm{~L}$ & 1 & $E$ & $\mathrm{~h}$ \\
\hline SUJEITO 7 & & & & \\
\hline SUJEITO 8 & L & $<$ & $E$ & $\mathrm{~h}$ \\
\hline SUJEITO 9 & L & $<$ & $E$ & $\bar{h}$ \\
\hline$\overline{\text { SUJEITO } 10}$ & U & 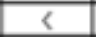 & $E$ & $E$ \\
\hline SUJEITO 11 & U & $<$ & $e$ & $h$ \\
\hline SUJEITO 12 & L & 3 & $E$ & $h$ \\
\hline
\end{tabular}

\begin{tabular}{|c|c|c|c|c|c|c|c|c|c|c|c|c|c|c|}
\hline \multicolumn{15}{|c|}{ LINGUA DE SINAIS (MND) } \\
\hline \multicolumn{3}{|c|}{1} & \multicolumn{4}{|c|}{2} & \multirow{2}{*}{$\langle 1<1=$} & \multicolumn{3}{|c|}{3} & \multirow[b]{2}{*}{$\langle k|=$} & \multicolumn{3}{|c|}{4} \\
\hline IFD & |FP| & MCF & $\langle 1<1=$ & IFD & IFP & MCF & & IFD & IFP & MCF & & |FD & IFP & MCF \\
\hline$E$ & e & e & $<$ & $E$ & $E$ & $E$ & $<$ & $E$ & e & e & $<$ & E & $\mathrm{E}$ & \\
\hline$E$ & $E$ & $\bar{E}$ & i & $\bar{E}$ & $\bar{E}$ & $=$ & & $F$ & $E$ & $E$ & 7 & $E$ & E & $\bar{E}$ \\
\hline$E$ & $\mathrm{E}$ & $\bar{E}$ & $\frac{1}{<}$ & $\bar{E}$ & $\bar{E}$ & $\mathrm{E}$ & 1 & $E$ & E & $E$ & i & $E$ & E & $\bar{E}$ \\
\hline$E$ & $E$ & $\bar{E}$ & $\bar{\zeta}$ & $\bar{E}$ & $E$ & $E$ & $<$ & $E$ & $E$ & $E$ & s & E & $\mathrm{E}$ & 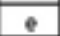 \\
\hline$E$ & $\bar{E}$ & $\mathrm{~h}$ & $<$ & E & $\bar{E}$ & $\mathrm{~h}$ & $<$ & $E$ & $E$ & $\bar{h}$ & < & E & $\mathrm{E}$ & $\mathrm{h}$ \\
\hline 5 & $E$ & $E$ & & $E$ & $E$ & $E$ & $<$ & $E$ & $E$ & $E$ & i & $\mathrm{E}$ & $\mathrm{E}$ & $\tau$ \\
\hline$E$ & $\mathrm{E}$ & E & $<$ & E & 6 & $E$ & & {[} & E & $\mathrm{E}$ & & $t$ & $\mathrm{E}$ & \\
\hline$E$ & $E$ & $\mathrm{~h}$ & $<$ & E & $E$ & $\mathrm{~h}$ & $<$ & $E$ & $E$ & $\mathrm{~h}$ & < & E & $\mathrm{E}$ & $\mathrm{h}$ \\
\hline$e$ & e & e & 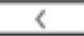 & $E$ & $E$ & $E$ & $\bar{\Sigma}$ & $E$ & $E$ & $E$ & s & $e$ & $e$ & $e$ \\
\hline$E$ & $E$ & $E$ & $<$ & $\mathrm{h}$ & $\bar{E}$ & $E$ & $\bar{k}$ & $e$ & $E$ & $E$ & $<$ & e & $e$ & \\
\hline $\mathrm{h}$ & $E$ & $E$ & 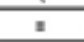 & h & $E$ & $E$ & $<$ & $h$ & $E$ & $E$ & $<$ & $\mathrm{E}$ & $E$ & \\
\hline
\end{tabular}

Fonte: Elaborada pelos autores

Figura 19. Notação da CM do sinal TARDE na produção de cada sujeito de acordo com o sistema de Johnson e Liddell $(2011,2012)$

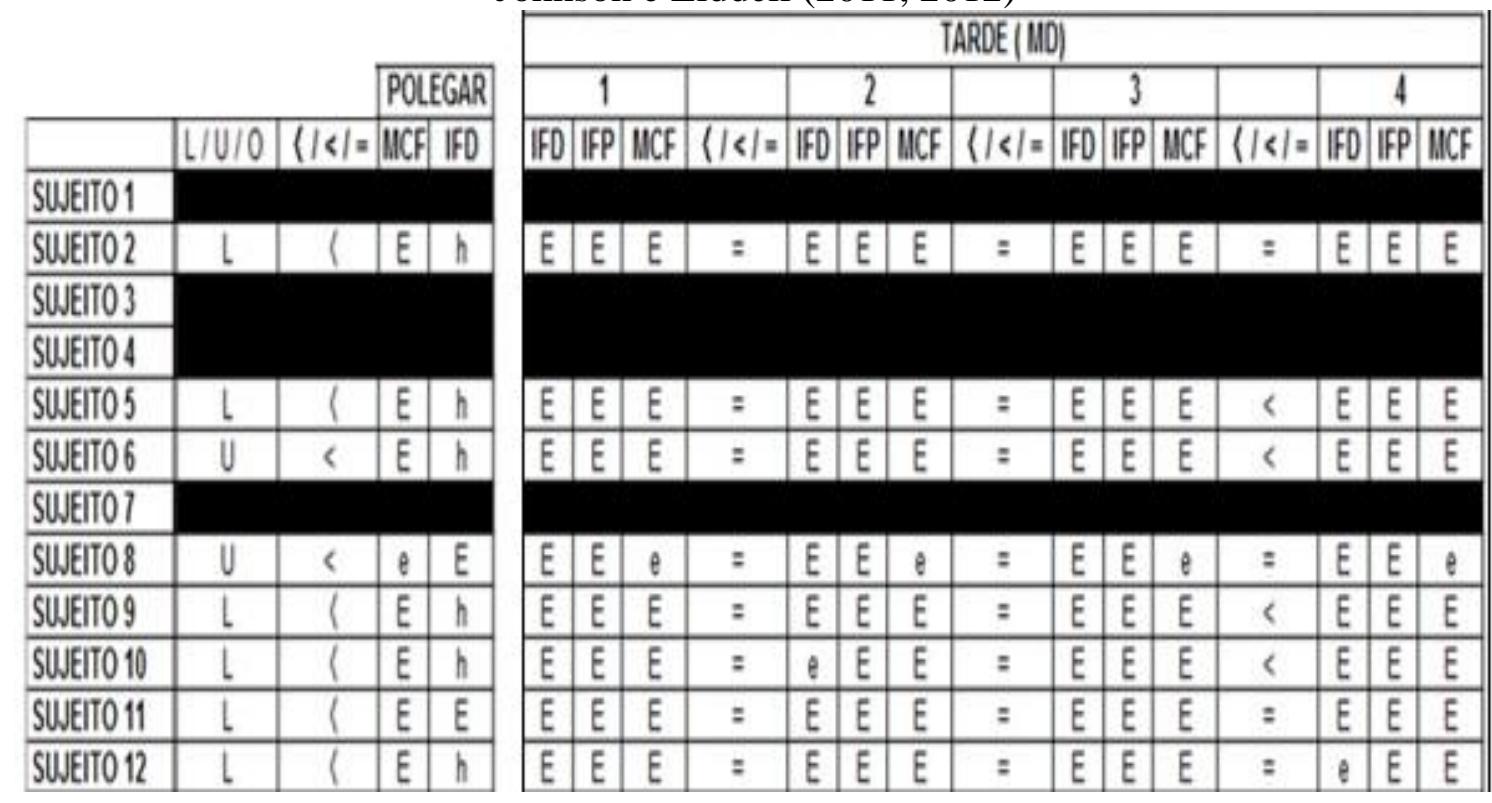

Fonte: Elaborada pelos autores 


\title{
Considerações finais
}

Com este estudo, objetivou-se demonstrar a maior capacidade de registro de detalhes articulatórios do parâmetro CM do sistema de notação e variação de Johnson e Liddell (2011, 2012). A partir de dados da libras, mostrou-se que sistemas que o antecederam, precisamente, o de Stokoe (1960) e o Liddell e Johnson (1989), não eram capazes de capturar, respectivamente, a variação no polegar e a variação em cada um dos outros dedos. Como visto, essa variação é satisfatoriamente capturada no sistema de Johnson e Liddell, uma vez que os autores propõem a notação e detalhe fonético de cada uma das juntas de cada um dos dedos separadamente, além do grau de adução entre dedos adjacentes.

Pode-se concluir, assim, que em um contínuo que vai do mais fonético ao mais fonológico, o sistema de Johnson e Liddell $(2011,2012)$ está no extremo mais fonético, o de Stokoe (1960), por representar a CM globalmente e ignorar o que não é distintivo, no mais fonológico, e o de Liddell e Johnson (1989), numa posição intermediária, já que captura a variação no polegar, mas ignora a variação nos demais dedos, tratando-os como um conjunto.

\begin{abstract}
Hand configuration is one of the articulatory parameters based on which signs can be analyzed. It refers, specifically, to the different states of the finger joints, potentially distinctive, but also subject to great intra and intersubjective variation. In this work, three proposed notation systems for this parameter are compared - Stokoe, Liddell and Johnson, and Johnson and Liddell - aiming to demonstrate, based on data from Libras, that the third one is more appropriate for the phonetic analysis of signed languages. The data from Libras analyzed here refers precisely to one of the three productions of 26 of the 60 signs originally collected by Xavier \& Barbosa from 12 deaf subjects (six men and six women) from the city of São Paulo. The criterion for selection of these signs was the presence of the hand configuration B (fingers open and joined by the sides) and the hand configuration 5 (fingers open and flat). With this, 185 productions were selected and analyzed. The results indicate that the Stokoe system has a more phonological character, while that of Johnson and Liddell, a more phonetic character, and that of Liddell and Johnson, an intermediate character between the first two.
\end{abstract}

Keywords: Notation. Hand configuration. Phonetics.

\section{Referências}

ALECRIM, E. C.; XAVIER, A. N. Análise da variação fonética em configurações de mão em libras. Revista Re-Unir. (a sair)

ALECRIM, E. C.; XAVIER, A. N. Descrição da variação fonético-fonológica em Libras. In: XIX 
Semana de Letras da UFPR, 2018, Curitiba. Cadernos da Semana de Letras. Curitiba: Setor de Humanas, 2017. v. 1. p. 41-53.

BATTISON, R. Lexical borrowing in American Sign Language. Silver Spring, MD: Linstok, 1978. 240p.

JOHNSON, R. E.; LIDDELL, S. K. Toward a phonetic representation of hand configuration: The thumb. Sign Language Studies, v. 12, n. 2, p. 316-333, 2012.

JOHNSON, R. E.; LIDDELL, S. K. Toward a phonetic representation of hand configuration: The fingers. Sign Language Studies, v. 12, n. 1, p. 5-45, 2011.

LIDDELL, S. K.; JOHNSON, R. E. (1989) American Sign Language: The Phonological Base. In: VALLI, C.; C. LUCAS (org.). (2000). Linguistic of American Sign Language: an introduction. Washington, D.C.: Clerc Books/Gallaudet University Press.

STOKOE, W. Sign Language Structure: An Outline of the Visual Communication Systems of the American Deaf'. Studies in Linguistics: Occasional Papers, 8, Washington, DC: Gallaudet University Press, 1960.

XAVIER, A. N.; BARBOSA, F. V. Variabilidade e estabilidade na produção de sinais da libras.

Domínios da Lingu@gem, v. 11, p. 983, 2017.

XAVIER, A. N.; BARBOSA, P. A. Diferentes pronúncias em uma língua não sonora? Um estudo da variação na produção de sinais da Libras, D.E.L.T.A, v. 30, n. 2, p. 371-413, 2014.

XAVIER, André Nogueira. Descrição fonético-fonológica dos sinais da língua brasileira de sinais (libras). 2006. 175 f. 2006. Dissertação (mestrado em Linguística) - Faculdade de Filosofia, Letras e Ciências Humanas, Universidade de São Paulo, São Paulo.

\section{Anexos}

Símbolos taxonômicos para da descrição dos dedos indicador, médio, anelar e mínimo adaptados de Liddell e Johnson (1989) e reproduzidos de Xavier (2006).

\begin{tabular}{|c|c|c|}
\hline Símbolo & & Configuração \\
\hline A & & os quatro dedos fechados e tocando as suas respectivas almofadas na \\
& & \\
\hline $\mathrm{S}$ & & \\
& & \\
\hline
\end{tabular}




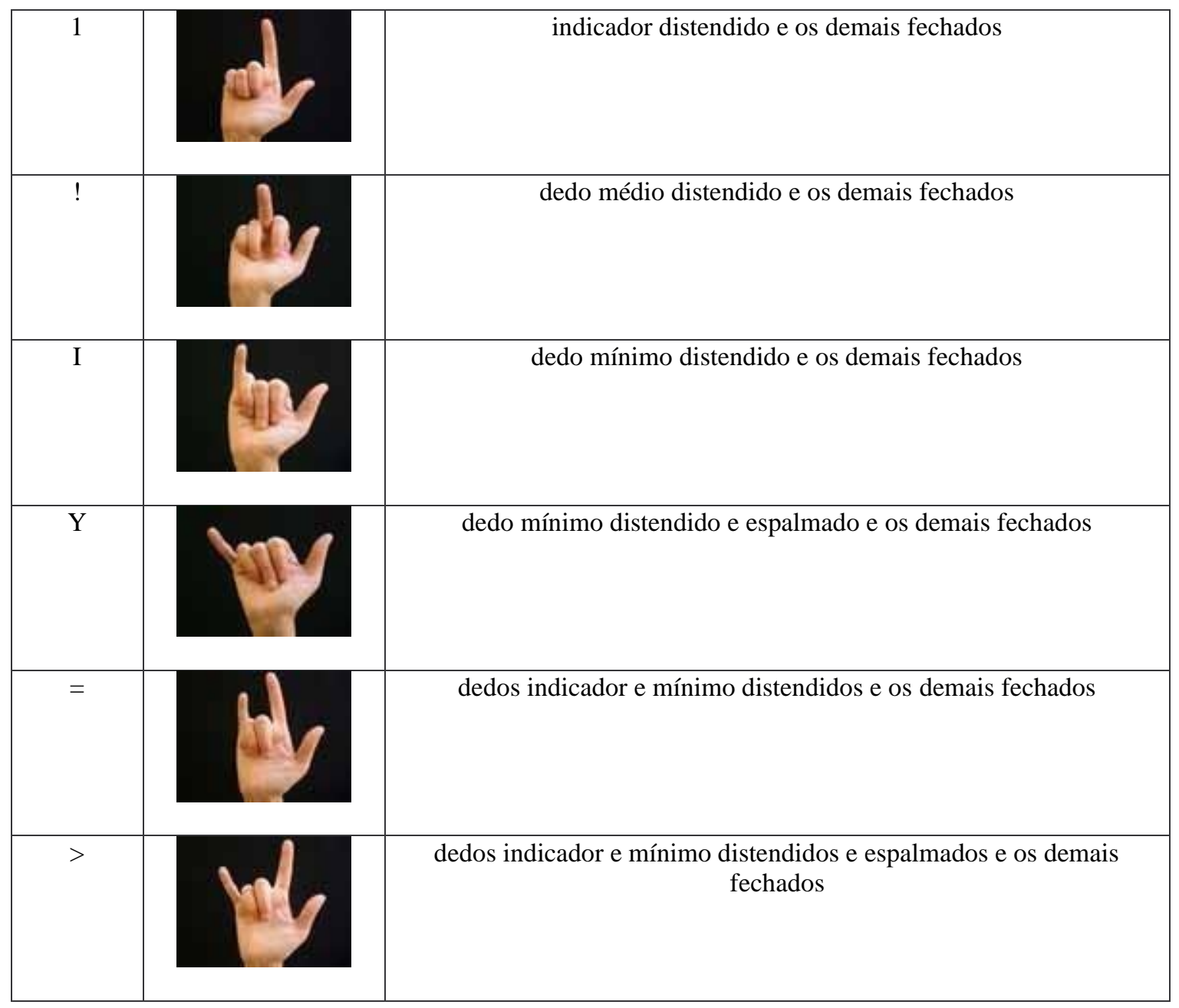

\begin{tabular}{|l|l|l|}
\hline $\mathrm{H}$ & dedos indicador e médio distendidos e unidos e os demais fechados \\
\hline $\mathrm{V}$ & dedos indicador e médio distendidos e espalmados e os demais fechados \\
\hline $\mathrm{K}$ & & parcialmente aberto \\
\hline
\end{tabular}




\begin{tabular}{|c|c|}
\hline $\mathrm{D}$ & dedo indicador distendido e os demais parcialmente abertos \\
\hline $\mathrm{R}$ & dedos indicador e médio cruzados e os demais fechados \\
\hline $\mathrm{R}$ & $\begin{array}{c}\text { dedos anelar e mínimos fechados, dedo médio distendido e indicador } \\
\text { cruzado sob este }\end{array}$ \\
\hline $\mathrm{W}$ & dedo mínimo fechado e todos os outros abertos e unidos \\
\hline 6 & dedo mínimo fechado e todos os outros abertos e espalmados \\
\hline 7 & dedo anelar fechado e todos os outros abertos e espalmados \\
\hline 8 & dedo médio fechado e todos os outros abertos e espalmados \\
\hline
\end{tabular}




\begin{tabular}{|l|l|c|}
\hline F & dedo indicador fechado e todos os outros abertos e unidos \\
\hline 9 & dedo indicador fechado e todos os outros abertos e espalmados \\
\hline B & os quatro dedos distendidos e unidos \\
\hline 4 & & \\
\hline $\mathrm{T}$ & & \\
\hline $\mathrm{N}$ & & \\
\hline
\end{tabular}

\section{Notas}

${ }^{i}$ Do inglês, American Sign Language.

ii Do inglês, unopposed.

iii Para uma descrição mais detalhada do modelo de Liddell e Johnson, ver Xavier (2006).

iv Este software permite anotar e transcrever, manual e semi-automaticamente, gravações de áudio ou vídeo. Download através do site https://tla.mpi.nl/tools/tla-tools/elan/download/. 